\title{
Gender stereotypes in occupational choice: a cross-sectional study on a group of Italian adolescents
}

This article was published in the following Dove Press journal:

Psychology Research and Behavior Management

18 April 2017

Number of times this article has been viewed

\section{Tiziana Ramaci ${ }^{\prime}$ \\ Monica Pellerone' \\ Caterina Ledda ${ }^{2}$ \\ Giovambattista Presti ${ }^{1}$ \\ Valeria Squatrito' \\ Venerando Rapisarda ${ }^{2}$}

'Faculty of Human and Social Sciences,

"Kore" University of Enna, Enna,

${ }^{2}$ Occupational Medicine, Department

of Clinical and Experimental Medicine,

University of Catania, Catania, Italy
Correspondence: Monica Pellerone Faculty of Human and Social Sciences, "Kore" University of Enna, Via Cittadella Universitaria s.n.c., Enna, Sicily 94100 , Italy

Tel +39329432 43II

Email monica.pellerone@unikore.it
Background: Gender beliefs represent cultural schemas for interpreting or making sense of the social and employment world, as they can influence attitudes, career aspirations, and the vocational decision process of young people, especially the adolescence.

Materials and methods: This study examined the influence of gender stereotypes on the choice of career in adolescents. A group of 120 students were recruited to complete an ad hoc questionnaire, Scale of Perceived Occupational Self-Efficacy, and Semantic Differentials. The objectives of the study were to analyze the relationship between occupational self-efficacy and professional preference; to measure the influence of independent variables, such as age and gender, on the representation that students have of themselves and of the profession; and to identify the predictor variables of self-efficacy in the vocational decision.

Results: Data showed that the distance between professional identity and social identity increases with age. Results underline that males seem to perceive themselves more self-efficient in military, scientific-technological, and agrarian professions than females. Furthermore, the type of job performed by parents appears to be a self-efficacy predictor variable in the choice of professions in the services area.

Conclusion: Individuals' perceived occupational self-efficacy, gender, age, and parents' profession have implications for exploratory behavior. The conditions that make gender differences salient are more likely to favor self-representations of the career and consistent assessments with these representations.

Keywords: adolescent, gender stereotypes, occupational choice

\section{Introduction}

Teens go through times of transition from one condition to another, such as middle school to college, the latter to university, and the state of being unemployed or employed.

Such moments of transition are stressful life events, which have the potential to influence one's personal and social identity. ${ }^{1-3}$ The ways in which each person faces the various transitions are influenced by gender, ${ }^{4}$ paths and personal experiences, ${ }^{5-7}$ and individual resources. ${ }^{8,9}$

Only during adolescence does identity become independent, along with the vocational decision-making process. The construction of identity in adolescence and the mechanisms by which they reach professional maturity bring teenagers to discover themselves, their skills and interests, and to make adequate academic and vocational choices.

The professional decision-making process is complex and dynamic during adolescence, and it is a skill that takes the form of a personal style of choice; teenagers 
with safe decision-making and good vocational self-efficacy have the opportunity to plan their careers and develop good vocational identity. ${ }^{10}$ Thus, the reflection on professional identity seems to be a turning point for the definition of life projects and the planning of a profession in adolescence.

In the setting of the research on career counseling, ${ }^{11}$ some of the literature is about the relationship between educational-occupational choice and self-representation of the career. The career decision is a construct that goes beyond the identification of an objectively correct profession; it appears to be full of individual and social meanings. ${ }^{12,13}$

In particular, the term career does not only refer to the working scope but also has different levels of involvement than, for example, the various aspects of development of the individual. A research tradition is in fact ascribable to the studies that consider a career as a journey through different stages, the life course paradigm. ${ }^{14,15}$ In this perspective, the focus is represented by age, as an element by which the operation of cultural and regulatory systems that define how the constraints and actions of the individual resources are regulated.

Another line of research is aimed at demonstrating the determinants of gender in the choice of the career, stressing that the career identity is formed and tends to be established in middle school. ${ }^{16}$

\section{Stereotypes and career choices}

In the career counseling setting, the literature examines the issue of gender differences and the role that mutual perceptions play in representing male or female behavior. ${ }^{17,18}$ These studies appear supported by the need to interpret gender stereotypes as an expression of social attitudes and gender preferences that guide the educational-professional choice. According to these studies, the activation of the stereotype would favor the accentuation of the similarities and differences; the stereotypical beliefs about the representation of male and female behavior; and the set of activities, roles, and traits that are most frequently attributed to females or males. ${ }^{19}$

Stereotypes represent a categorization strategy that individuals use to simplify a world of varied experiences, and they produce two basic consequences; on the one hand, they simplify the reality that, once acquired, they tend to resist to change, since it was reinforced by a series of cognitive, behavioral, and language mechanisms; on the other hand, they lead to misinterpretation. Their use can lead, in fact, to a loss of accuracy of information, underestimating or overestimating the degree of association between the stereotypical tract and the reference category. This is due to the distorting character of their stereotypical expectations. ${ }^{20}$

The role of stereotypes in the choice of the professions appropriate to the gender has been the subject of study aimed at verifying the stereotypes linked to professional roles. ${ }^{21}$ Stereotyped beliefs, in this perspective, accentuating the association between particular professional categories and gender, ${ }^{22}$ influence the preferences toward educational-professional routes deemed more appropriate to the male and/ or female gender.

High levels of self-efficacy expressed toward the more gender-related professions have been found in this direction. ${ }^{23}$ For example, Aros et $\mathrm{al}^{24}$ found that adolescents tend to perceive realistic professions as more appropriate to the male gender, such as drivers and some enterprising occupations such as building contractors, whereas social occupations are more appropriate to the female gender, such as teachers, midwives, or being a hostess or public relations officer.

The literature has also confirmed that students express professional interests consistent with stereotypical patterns, in particular, males prefer male occupations, such as military professions, while females, the typically female ones such as teachers and nurses. ${ }^{25}$

Similarly, the study by $\mathrm{Ji}$ et $\mathrm{al}^{26}$ showed that realistic professions are considered typically masculine and therefore preferred by males; social and artistic occupations are considered traditionally feminine and are thus preferred by females. At the same time, females express greater levels of self-efficacy for artistic and social professions, while males do so for realistic professional activities.

These research studies allow us to explain the persistence of the phenomenon of the educational and professional segregation of gender, which tends to consider exclusively professional options connected to gender typing. In particular, during childhood, teachers and parents, through their expectations about behavior, roles, and attitudes of children, tend to influence the gender socialization processes that guide males and females toward professions deemed appropriate to the belonging gender. ${ }^{27,28}$ In line with gender stereotypes, teachers and family members offer males more learning opportunities in mathematics and science; they attribute them roles of leadership, initiative, and independence. ${ }^{29-31}$ Females are more tempted to read, more stimulated by social relations, and discouraged toward the approach attempts of mathematical activities, which are considered most suited to their male peers. ${ }^{21}$

Parents' and teachers' stereotyped beliefs guide the future attitudes of males toward typically male disciplines such as 
mathematics, ${ }^{32}$ influencing the levels of self-efficacy and subsequent career choices. ${ }^{33}$ As a result, females tend to regard mathematics as belonging to a particularly male environment and show a less positive attitude toward this discipline. All this will tend to influence, in both male and female students, the design of their professional future..$^{34,35}$

Based on this literature, the aim of this study is to analyze the relationship between occupational self-efficacy and professional preference; to measure the influence of the independent variables, such as age and gender, on the representation that students have of themselves and of the profession; and to identify the predictor variables of selfefficacy in the vocational decision.

Specific objectives and hypotheses are

1. to measure the relationship between perceived occupational self-efficacy and professional preference, assuming the presence of a positive correlation between selfefficacy in military professions and practical workshops and between self-efficacy in the services occupations area and the possibility to work in groups;

2. to assess the influence of the independent variables on the representation that students have of themselves and of the profession; in particular, it is assumed that the distance between professional identity and social identity increases with age and that this distance becomes more evident in males than in females;

3. to identify the predictor variables of the perceived occupational self-efficacy; in particular, confirming the literature, it is assumed that between the predictors there are gender, age, parents' profession, and motivation to the educational-professional choice. ${ }^{36}$

\section{Materials and methods Study design and participants}

A cross-sectional study involving students attending the IV and $\mathrm{V}$ classes was conducted in an Italian high school. The general content of the high school curriculum sets a list of basic required courses for high school graduation; these include the following: 1) literature, 2) English and Foreign languages, 3) mathematics and scientific subjects, and 4) social and human sciences.

In this study, 126 students, recruited as participants in a training course as part of a project PON (National Operational Plan), were asked to complete the self-report questionnaires. Since $5 \%$ of the students refused to participate in the survey, the questionnaires were administered to 120 students $(95 \%$ response rate).
The data collection lasted about 3 months, although the entire research project lasted for 1 year, conducted between 2015 and 2016. The aims of the study and the questionnaire were explained to the participants. The questionnaire was distributed by qualified researchers, and students were given 20 minutes to complete it. The researcher remained at a distance, to guarantee anonymity.

Parents of participants were informed about the study aims and procedures and gave their written informed consent to have them participate.

The internal review board (IRB) of Faculty of Human and Social Sciences at the "Kore" University of Enna approved the present research.

\section{Measures}

The instruments used were the following: "ad hoc questionnaire," "Scale of Perceived Occupational Self-Efficacy," ${ }^{37}$ and "Semantic Differentials." 38

The ad hoc questionnaire was divided into three parts: the first designed to detect biographical data (gender, age, institution of origin, and parents' occupation); the second was regarding the evaluation of options after graduation; and the third helped to detect the reasons for the choice, using a range from 1 "strongly disagree" to 10 "strongly agree".

The Scale of Perceived Occupational Self-Efficacy measures the degree to which young people consider themselves able to undertake a large number of professional roles and follow the professional route that leads to such roles, using a range from 1 "strongly disagree" to 6 "strongly agree". The scale consists of 50 items related to numerous professional options, corresponding to six professional areas: medical/ educational (M/E), scientific/technological $(\mathrm{S} / \mathrm{T})$, services (S), artistic/literary (A/L), agricultural/artisan (A/A), and military $(\mathrm{M})$. The instrument has a good reliability for the following areas: $\mathrm{M} / \mathrm{E}$ (Cronbach's alpha $=0.90), \mathrm{S} / \mathrm{T}$ (Cronbach's alpha $=0.85), \mathrm{S}($ Cronbach's alpha $=0.89), \mathrm{A} / \mathrm{L}$ (Cronbach's alpha $=0.86), \mathrm{A} / \mathrm{A}$ (Cronbach's alpha $=0.80)$, and $\mathrm{M}$ (Cronbach's alpha $=0.78) .{ }^{37}$

Semantic Differentials were used to investigate three selfrepresentations and one dimension relative to profession: real (ie, "How I am..."), social (ie, "How I think people see me"), future self-representation (such as "The future is..."), and profession (like "The profession is..."). They are formed by 34 couples of polar adjectives, each evaluable on a 7-point scale (coded from -3 to $3+$, midpoint $=0$ ). The semantic differential is a psychometric instrument based on the analysis of implicit affective resonances in the semantic qualification of concepts. ${ }^{38,39}$ This technique, conceived by Osgood et al, ${ }^{40}$ 
is based on the subjective and direct description of personal characteristics, which individuals have of themselves. It consists of a concept to be evaluated and in a series of opposite adjectives, separated by a graphic scale. Semantic Differential has a good internal consistency, on all scales: the Real Self (Cronbach's alpha $=0.821$ ), the Ideal Self (Cronbach's alpha $=0.900)$, the Social Self $($ Cronbach's alpha $=0.881)$, and the Professional dimension (Cronbach's alpha $=0.863) .{ }^{40}$

\section{Statistical analysis}

Descriptive statistics used absolute frequencies and percentages for categorical variables and mean and standard deviation (SD) for quantitative variables. The univariate analysis of variance (ANOVA one-way) was conducted in order to measure the influence of the gender variable on the importance attributed by participants to the reasons behind the choice and on the perceived occupational self-efficacy.

The Pearson's chi-square test was used to evaluate the relationship between perceived self-efficacy and professional preference.

Euclidean distances were calculated to measure the distances between the self-dimensions related to the social identity and the professional identity.

Linear multiple regression analyses were conducted, assuming that among the predictor variables to the professional self-efficacy there were gender and age of the student, type of institute, parents' type of occupation (sociodemographic level); identity dimensions that is real, social, ideal, and professional (individual level); and the reasons for choosing the school curriculum, in particular the influence of family and peer-group (social level).

A significance level of 0.05 was used. All data analyses were conducted using SPSS 22.0.

\section{Results}

The study group was formed of 120 participants, of whom 45 were males (37.5\%) and 75 were females (62.5\%), aged

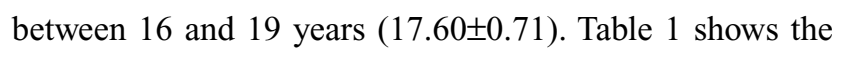
main characteristics of the study population.

In reference to the parents' profession, regarding fathers: $32.5 \%$ were office workers, $19.2 \%$ employed, $19.2 \%$ were

Table I Distribution of participants by type of institute

\begin{tabular}{lll}
\hline Area & Males (\%) & Females (\%) \\
\hline Literature & 11.1 & 13.3 \\
English and Foreign languages & 2.2 & 6.7 \\
Mathematics and scientific subjects & 84.4 & 61.3 \\
Social and human sciences & 2.2 & 18.7 \\
\hline
\end{tabular}

freelance professionals, and $13.3 \%$ were enrolled in law enforcement; in relation to the mothers' profession: $37.5 \%$ were housewives, $22.5 \%$ were teachers, $15 \%$ were employed, and $9.2 \%$ were freelancers.

\section{Choice upon graduation}

Regarding the question "Indicate your choice after graduation" among the answers chosen by girl students, many preferred to continue their education; males instead preferred non-university pathways, for example, military careers. Interestingly, $41.4 \%$ of the group (of which $26.7 \%$ were males and $14.7 \%$ were females) had not made a choice (Table 2).

In reference to the reason of the choice, through the focus group technique, 16 factors were identified, namely, family expectations, influential friendships, other people's advice, employment prospects, personal interests, possible future earnings, costs of university courses, access criteria to university courses, number of students, proximity of the location, prestige of the university, working in groups, university study plan, the presence of practical workshops, duration of the courses, and mobility period abroad. The univariate analysis of variance (ANOVA one-way) was conducted in order to measure the influence of the gender variable on the importance attributed by participants to the reasons behind the choice (Table 3 ). The analysis of the average scores showed that more females than males gave a greater importance to the access conditions (males: $\mathrm{M}=5.44$, $\mathrm{SD}=2.96$; females: $\mathrm{M}=6.45, \mathrm{SD}=2.50$ ), the number of members of the university course (males: $\mathrm{M}=4.42, \mathrm{SD}=3.07$; females: $\mathrm{M}=5.73, \mathrm{SD}=3.13$ ), but above all to the presence of practical workshops (males: $\mathrm{M}=6.56, \mathrm{SD}=3.05$; females: $\mathrm{M}=7.72, \mathrm{SD}=2.25$ ).

\section{Perceived occupational self-efficacy}

With regard to the scale of perceived occupational selfefficacy, the ANOVA showed the influence of the gender variable on the perceived occupational self-efficacy (Table 4). In particular, the analysis of the average scores showed that males manifested a higher level of self-efficacy in

Table 2 Frequency distribution of the scores related to the choice after graduation

\begin{tabular}{lll}
\hline Measures & Males (\%) & Females (\%) \\
\hline Student has not currently made a choice & 26.7 & 14.7 \\
Humanistic courses & 13.3 & 21.3 \\
Scientific courses & 37.8 & 56.0 \\
Professional paths (non-university) & 22.2 & 8.0 \\
\hline
\end{tabular}

Note: The non-academic career paths indicated by the students are the following: photography classes, computer, restorer, and military career. 
Table 3 Breakdown of the univariate effects related to the reasons behind the choice, with respect to the gender variable

\begin{tabular}{lll}
\hline Measures & $\boldsymbol{F}$ & $\mathbf{p}$-value \\
\hline Family expectations & 0.04 & 0.84 \\
Influential friendships & 2.11 & 0.15 \\
Other people's advice & 0.95 & 0.33 \\
Employment prospects & 3.31 & 0.07 \\
Personal interests & 0.46 & 0.50 \\
Possible future earnings & 2.58 & 0.11 \\
Costs of university & 1.79 & 0.18 \\
Access criteria to university & 3.98 & $0.05^{*}$ \\
Number of students & 4.98 & $0.03^{*}$ \\
Proximity of the location & 1.43 & 0.23 \\
Prestige of the university & 0.03 & 0.85 \\
Working in groups & 0.90 & 0.35 \\
University study plan & 2.38 & 0.13 \\
Practical workshops & 5.72 & $0.02^{*}$ \\
Duration of the courses & 0.09 & 0.76 \\
Mobility period abroad & 0.48 & 0.49 \\
\hline Notes: &
\end{tabular}

Notes: * $p<0.05$, two-tailed; Gdl (1.1 I8).

Table 4 Breakdown of the univariate effects related to the perceived occupational self-efficacy, with respect to the gender variable

\begin{tabular}{|c|c|c|c|}
\hline Measures & Gdl (1.II8) & $\boldsymbol{F}$ & $p$-value \\
\hline Medical/educational & & 2.63 & 0.11 \\
\hline Scientific/technological & & 16.22 & $0.00 * * *$ \\
\hline Services & & 0.84 & 0.36 \\
\hline Artistic/literary & & 0.18 & 0.67 \\
\hline Agricultural/artisian & & 7.65 & $0.0 I^{* *}$ \\
\hline Military & & 5.62 & $0.02 *$ \\
\hline
\end{tabular}

scientific profession (males: $\mathrm{M}=3.28, \mathrm{SD}=1.44$; females: $\mathrm{M}=2.32, \mathrm{SD}=1.14$ ), agricultural (males: $\mathrm{M}=2.79, \mathrm{SD}=1.25$; females: $\mathrm{M}=2.18, \mathrm{SD}=1.08$ ), and military professions (males: $\mathrm{M}=3.37, \mathrm{SD}=1.59$; females: $\mathrm{M}=2.69, \mathrm{SD}=1.47$ ) compared with females.

\section{Relationship between perceived self-efficacy and professional preference}

According to the literature, the present study showed that the large number of members on a course of study correlated with the perception of self-efficacy in medical professions $(r=0.21, p<0.05)$; similarly the criterion of access $(r=0.20$, $p<0.05)$ and the ability to work in groups $(r=0.18, p<0.05)$ correlated with the perception of self-efficacy in professions addressed to services.

Negative correlations emerged between the choice made on the basis of the type of subjects and the perception of self-efficacy in technology professions $(r=-0.19, p<0.05)$ and between the ability to perform hands-on labs and perception of self-efficacy in military professions $(r=-0.18, p<0.05)$.
Finally, a negative correlation was also found between perception of self-efficacy in the agriculture/artisan area and importance attributed to earnings $(r=-0.22, p<0.05)$.

\section{Influence of independent variables on the representation of the Identity}

In reference to the last part of the questionnaire, which included the use of four semantic differentials, the analysis of the mean scores showed how the ideal identity $(5.68 \pm 0.92)$ is evaluated more positively than the professional one (5.43 \pm 0.72$)$, a difference that appeared statistically significant $(\mathrm{t}=-1.50, p<0.0001)$.

The dimension of the professional identity, however, appears to be evaluated positively than the other two dimensions of identity: real $(4.80 \pm 0.62)$ and social $(4.70 \pm 0.72)$; a difference that appeared statistically significant for both identity dimensions (social identity: $\mathrm{t}=6.13, p=0.001$; real identity: $\mathrm{t}=5.50, p=0.001$ ).

Statistical analysis of the distances between the three dimensions of identity (real, ideal, and social) and the relative dimension to the profession (professional identity) detected that these distances are (Figure 1): minor compared to the social identity (2.17 \pm 0.68$)$, and more for the ideal identity $(2.34 \pm 1.21)$ and real identity $(2.19 \pm 0.61)$. This indicated that the professional identity is considered much more similar to the social one compared to the ideal and the real ones.

Subjects, therefore, tend to regard the profession much more like the way they are "perceived by others" rather than the ideal and real self-representation.

Moreover, the data showed a significant influence of gender and age variables; the distance between the dimension of the social and professional identity was lower in males than in females $(\mathrm{t}=1.48 ; p=0.05)$; the distance between professional and the other two dimensions of identity, real and

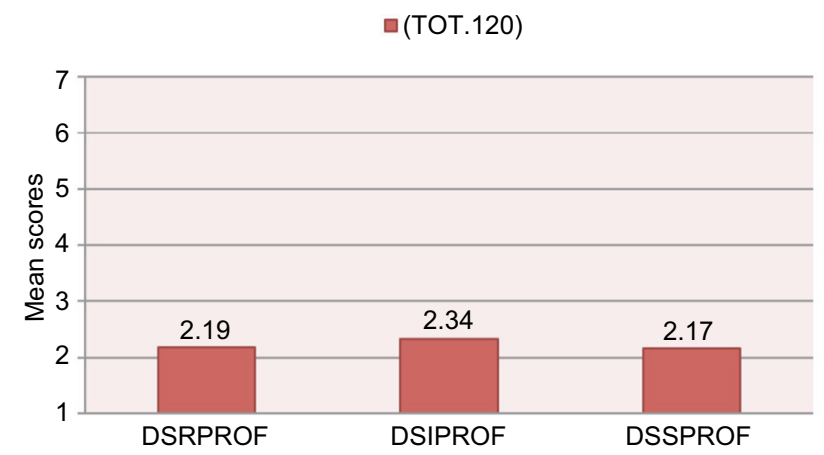

Figure I Euclidean distances between self (real, ideal, and social) and professional identity.

Note: Comparisons (" $t$ " for repeated tests): [DSRPROF.//DSSIPROF. $p=0.026$ ]; ; [DSRPROF.//DSSSPROF. $p<0.00$ I]; [DSIPROF//DSSPROF $p=0.109$ ].

Abbreviations: DSRPROF, distance between real self and professional self; DSIPROF, distance between ideal self and professional self; DSSPROF, distance between social self and professional self. 
social, significantly increased with the transition from class IV to V (real identity: $\mathrm{t}=-2.11, p=0.040$; social identity: $\mathrm{t}=-3.36, p=0.002$ ).

This score would seem to confirm the role of social influence, according to which students, especially males, tend to take into account the opinions of others rather than choosing for themselves.

\section{Predictive variables to the perceived self- efficacy in the vocational choice}

Linear multiple regression analyses were conducted in order to verify the predictive self-efficacy variables in choosing. Referring to self-efficacy in the scientific/technological area $(\mathrm{S} / \mathrm{T})$, Table 5 shows that among the predictors there are gender, father's profession, and friendships.

Referring to self-efficacy in the area of services (S), the regression analysis showed that the only predictive variable is the type of mother's profession, explaining $15 \%$ of the total variance (Table 6).

Referring to self-efficacy in the agricultural/artisan area (A/A), Table 7 shows that among the predictive variables there are gender, mother's profession, and friendships.

\section{Discussion and conclusion}

This study investigated the role of gender stereotypes in choice of the career in adolescents as well as the perception of gender of a career, and specifically self-efficacy and professional preference; the dimension of the professional identity and self-representation as predictive variables of decision.

In reference to the reason of the vocational choice, the data showed that females more frequently manifest the desire to continue their education, males instead prefer non-university pathways, for example, military careers; furthermore, more females than males give significantly greater importance to employment prospects, access conditions, and to the number of members of the university course, but above all, to the presence of practical workshops.

These results are consistent with recent literature that explains the persistence of the phenomenon of the educational professional segregation of gender, which tends to consider exclusively professional options connected to gender typing, ${ }^{41-43}$ reducing the range of potentially considerable options and will tend to influence, in both male and female students, the design of their professional future, above all during adolescence. ${ }^{34,44,45}$

Table 5 Model summary of regression analyses that predicts self-efficacy in the scientific/technological area

\begin{tabular}{|c|c|c|c|c|c|c|c|}
\hline Variables & $R^{2}$ & Adjusted $R^{2}$ & No adjusted $B$ & SE & B & $T$ & $p$-value \\
\hline Gender & 0.46 & 0.21 & 0.03 & 0.18 & 0.02 & 0.16 & 0.88 \\
\hline Age & & & 0.84 & 0.26 & 0.31 & 3.24 & 0.00 \\
\hline Type of institute & & & 0.00 & 0.14 & 0.00 & 0.00 & 1.00 \\
\hline Mother's job & & & -0.05 & 0.06 & -0.08 & -0.81 & 0.42 \\
\hline Father's job & & & 0.29 & 0.11 & 0.20 & 2.13 & 0.04 \\
\hline Family expectations & & & -0.09 & 0.06 & -0.18 & -1.60 & 0.11 \\
\hline Influential friendships & & & 0.14 & 0.05 & 0.28 & 2.58 & 0.01 \\
\hline Other people's advice & & & -0.05 & 0.05 & -0.10 & -0.95 & 0.35 \\
\hline Real identity & & & 0.19 & 0.23 & 0.09 & 0.82 & 0.41 \\
\hline Ideal identity & & & -0.13 & 0.16 & -0.09 & -0.80 & 0.42 \\
\hline Social identity & & & 0.11 & 0.21 & 0.06 & 0.54 & 0.59 \\
\hline Professional identity & & & 0.13 & 0.20 & 0.07 & 0.67 & 0.51 \\
\hline
\end{tabular}

Abbreviation: SE, standard error.

Table 6 Model summary of regression analyses that predicts self-efficacy in the services area

\begin{tabular}{|c|c|c|c|c|c|c|c|}
\hline Variables & $R^{2}$ & Adjusted $R^{2}$ & No adjusted $B$ & SE & B & $T$ & $p$-value \\
\hline Gender & \multirow{12}{*}{0.43} & \multirow{12}{*}{0.18} & -0.05 & 0.15 & -0.03 & -0.34 & 0.73 \\
\hline Age & & & -0.10 & 0.23 & -0.04 & -0.43 & 0.67 \\
\hline Type of institute & & & 0.28 & 0.12 & 0.22 & 2.24 & 0.03 \\
\hline Mother's job & & & -0.07 & 0.06 & -0.12 & -1.20 & 0.23 \\
\hline Father's job & & & 0.23 & 0.07 & 0.31 & 3.26 & 0.00 \\
\hline Family expectations & & & 0.03 & 0.05 & 0.06 & 0.52 & 0.61 \\
\hline Influential friendships & & & 0.04 & 0.05 & 0.09 & 0.78 & 0.44 \\
\hline Other people's advice & & & 0.01 & 0.04 & 0.02 & 0.18 & 0.86 \\
\hline Real identity & & & 0.01 & 0.20 & 0.00 & 0.03 & 0.98 \\
\hline Ideal identity & & & -0.17 & 0.14 & -0.14 & -1.24 & 0.22 \\
\hline Social identity & & & 0.07 & 0.18 & 0.04 & 0.36 & 0.72 \\
\hline Professional identity & & & -0.01 & 0.17 & -0.01 & -0.07 & 0.94 \\
\hline
\end{tabular}

Abbreviation: SE, standard error. 
Table 7 Model summary of regression analyses that predicts self-efficacy in the agricultural/artisan area

\begin{tabular}{|c|c|c|c|c|c|c|c|}
\hline Variables & $R^{2}$ & Adjusted $R^{2}$ & No adjusted $B$ & SE & B & $T$ & $p$-value \\
\hline Gender & 0.48 & 0.24 & -0.03 & 0.15 & -0.02 & -0.16 & 0.87 \\
\hline Age & & & 0.88 & 0.23 & 0.36 & 3.90 & 0.00 \\
\hline Type of institute & & & 0.29 & 0.12 & 0.22 & 2.38 & 0.02 \\
\hline Mother's job & & & -0.06 & 0.06 & -0.11 & -1.13 & 0.26 \\
\hline Father's job & & & 0.21 & 0.07 & 0.28 & 3.02 & 0.00 \\
\hline Family expectations & & & 0.07 & 0.05 & 0.15 & 1.36 & 0.18 \\
\hline Influential friendships & & & -0.07 & 0.05 & -0.16 & -1.51 & 0.13 \\
\hline Other people's advice & & & -0.07 & 0.04 & -0.16 & -1.61 & 0.11 \\
\hline Real identity & & & 0.19 & 0.20 & 0.10 & 0.96 & 0.34 \\
\hline Ideal identity & & & -0.11 & 0.14 & -0.08 & -0.77 & 0.44 \\
\hline Social identity & & & -0.11 & 0.18 & -0.07 & -0.61 & 0.54 \\
\hline Professional identity & & & 0.03 & 0.17 & 0.02 & 0.19 & 0.85 \\
\hline
\end{tabular}

Abbreviation: SE, standard error.

These latter relationships were tested, in the present study, according to the role that gender stereotypes assume in career decision. The data have confirmed that the conditions which make gender differences salient are more likely to favor career self-representations and self-assessments consistent with these prejudices. ${ }^{46,47}$ In particular, the data show that more males than females perceive themselves self-effective in military, scientific/ technological, and agricultural/artisan professions. These results confirm the literature that underlines that students express professional interests consistent with stereotypical patterns, in particular, males prefer male occupations, such as realistic professions, ${ }^{48}$ while females, the typically female ones such as teachers and nurses, which are social and artistic occupations.

In reference to the identity development, it is interesting how, in the present study, the real identity increases when switching from IV to V class; data are consistent with the literature that emphasizes the presence of a greater development of identity and respective awareness of the self with increasing age, above all in the Italian context. ${ }^{49,50}$

Finally, the results show that being a young adolescent man, with his father's job characterized by a profitable and prestigious profession, and having a broad network of friends are predictive of the choice of a scientific/technological school curriculum. In contrast to this, being a young adolescent, having a father who works in the artisan area, and attending an Institute of Social and Human Sciences are predictive of an agricultural/artisan choice. The only predictive variables of the choice of a social school curriculum are the father's profession, characterized by relationships of help and contact with others, and above all, attending an Institute of Social and Human Sciences.

These results confirm the role of stereotypes present in the educational and domestic environment; in particular, they underline as parents and teachers implement, often unconsciously, the gender socialization processes that guide adolescents toward professions deemed appropriate to the belonging gender.

The findings, more generally, indicate the importance of focusing on the role of gender stereotypes, present also in the educational and domestic environment in vocational choice. ${ }^{51,52}$ These findings enhance the centrality of the moment of choice that may find support in a counseling service, ${ }^{52}$ which increases a more conscious approach in students. The theme calls for a wide-ranging discussion on the redesign of the curricular school activities and on the school organizational procedures rather than the function of career counseling and career decision, with which the school could meet periodically to such bias.

\section{Disclosure}

The authors declare that the present research has not had commercial or financial relationships that could be represented as a potential conflict of interest. The authors report no other conflicts of interest in this work.

\section{References}

1. Gottfredson LS, Lapan RT. Assessing gender-based circumscription of occupational aspirations. J Career Assess. 1997;5(4):419-441.

2. Baubion-Broye A, Le Blanc A. L'incertitude dans les transitions: nouvelles approches: présentation [The uncertainty in the transitions: new approaches: presentation]. L'Orientation Scolaire et Professionnelle. 2001;30(1):3-8.

3. Haynie DL, Beck KH, Crump AD, et al. Parenting strategies regarding teen behavior: parent and teen perceptions. Am J Health Behav. 1999; 23(6):403-414.

4. Basow SA. Gender: Stereotypes and Roles. Belmont, CA: Thomson Brooks/Cole Publishing Co; 1992.

5. Amati M, Tomasetti M, Ciuccarelli M, et al. Relationship of job satisfaction, psychological distress and stress-related biological parameters among healthy nurses: a longitudinal study. JOccup Health. 2010;52(1): $31-38$.

6. Craparo G, Gori A, Mazzola E, Petruccelli I, Pellerone M, Rotondo G. Posttraumatic stress symptoms, dissociation, and alexithymia in an Italian sample of flood victims. Neuropsychiatr Dis Treat. 2014;10: 2281-2284. 
7. Pellerone M, Iacolino C, Mannino G, Formica I, Zabbara SM. The influence of Parenting on Maladaptive Cognitive Schema: a crosssectional research on a group of adults. Psychol Res Behav Manag. 2017; 10:47-58.

8. Pellerone M, Tolini G, Polopoli C. Parenting, identity development, internalizing symptoms and alcohol use. A cross-sectional study in a group of Italian adolescents. Neuropsychiatr Dis Treat. 2016;12: 1769-1778.

9. Specchiale A, Attinà AN, Maria GD, et al. Pilot study on the role of psychosocial aggression in a sample of cops and robbers. Acta Med Mediterr. 2013;29(3):407-410.

10. Pellerone M. Influence of identity, congruence of interest and coping strategy on decision making process. Proc Soc Behav Sci. 2015;191: 1344-1348.

11. Savickas ML. Guida teorica e metodologica per il XXI secolo [Theorical and Methodological Guide for the XXI Century]. Trento: Erikson; 2014. Italian.

12. Di Fabio A, Palazzeschi L, Levin N, Gati I. The role of personality in the career decision-making difficulties of Italian young adults. J Career Assess. 2015;23:281-293.

13. Farmer RL. Neuroscience and Social Work Practice: The missing Link. London: SAGE Publications; 2008.

14. Olagnero M. Vite nel tempo. La ricerca biografica in sociologia [Lives in Time: The Biographical Research in Sociology]. Roma: Carocci; 2004. Italian.

15. Saraceno C. Età e corso della vita [Age and lifetime]. Bologna: Il Mulino; 2001. Italian.

16. Pringle R. Bureaucracy, rationality and sexuality: the case of secretaries. In: Hearn J, Sheppard D, Tancred-Sheriff P, Burell G, editors. The Sexuality of Organization. Newbury Park, CA: SAGE; 1989: $158-177$.

17. Correll SJ, Kelly EL, O'Connor LT, Williams JC. Redesigning, redefining word. Work Occup. 2014;418(1):3-17.

18. Hadjar A, Aeschlimann B. Gender stereotypes and gendered vocational aspirations among Swiss secondary school students. Rev Educ Res. 2015;57(1):22-42

19. Berndt TJ, Heller KA. Gender stereotypes and social inferences: a developmental study. J Pers Soc Psychol. 1986;50(5):889.

20. Arcuri L, Cadinu MR. Gli stereotipi: dinamiche psicologiche e contest delle relazioni sociali [Stereotypes, Psychological Dynamics and Contexct in Social Relationship]. Bologna: Il Mulino; 1998. Italian.

21. Heppner MJ, Dong-gwi L, Heppner PP, et al. The role of problemsolving appraisal in the process and outcome of career counseling. $J$ Vocat Behav. 2004;65(2):217-238.

22. Wilbourn MP, Kee DW. Henry the nurse is a doctor too: implicitly examining children's gender stereotypes for male and female occupational roles. Sex Roles. 2010;62(9-10):670-683.

23. Ramaci T, Pellerone M, Iacolino C. Stress-related diseases: significant influence on the quality of life at workplaces. Eur Proc Soc Behav Sci. 2016; 8:29-38.

24. Aros JR, Henly GA, Curtis NT. Occupational sex-type and sex differences in vocational preference-measured interest relationships. $J V B$. 1998;53:227-242.

25. Zysberg L, Berry DM. Gender and students' vocational choices in entering the field of nursing. Nurs Outlook. 2005;53(4):193-198.

26. Ji PY, Lapan RT, Tate K. Vocational interests and career efficacy expectations in relation to occupational sex-typing beliefs for eighth grade students. J Career Dev. 2004;31(2):143-154.

27. Pellerone M, Craparo G, Tornabuoni Y. Relationship between parenting and cognitive schemas in a group of male adult offenders. Front Psychol. 2016;7:302.

28. Iacolino $\mathrm{C}$, Pellerone $\mathrm{M}$, Pace $\mathrm{U}$, et al. Family functioning and disability: a study on Italian parents of disabled children. Eur Proc Soc Behav Sci. 2016;8:39-52.

29. Eccle JS. Understanding women's educational and occupational choices. Psychol Women Q. 1994;18(4):585-609.
30. Jacobs JE, Chhin CS, Bleeker MM. Enduring links: parents' expectations and their young adult children's gender-typed occupational choices. Educ Res Eval. 2006;12(4):395-407.

31. Pellerone M, Passanisi A, Bellomo MFP. Identity development, intelligence structure, and interests: a cross-sectional study in a group of Italian adolescents during the decision-making process. Psychol Res Behav Manag. 2015;8:239-249.

32. Boekaerts M, Seegers G, Vermeer H. Solving math problems: where and why does the solution process go astray? Educ Studies Math. 1995;28(3):241-262.

33. Bleeker MM, Jacobs JE. Achievement in math and science: do mothers' beliefs matter 12 years later? J Educ Psychol. 2004;96(1):97.

34. Steele J, Barling J. Influence of maternal gender-role beliefs and role satisfaction on daughters' vocational interests. Sex Roles. 1996;34(9-10):637-648.

35. Pellerone M, Ramaci T, Parrello S, Guariglia P, Giaimo F. Psychometric properties and validation of the Italian version of the Family Assessment Measure - short version - third edition in a nonclinical sample. Psychol Res Behav Manag. 2017;10:69-77.

36. Ferry TR, Fouad NA, Smith PL. The role of family context in a social cognitive model for career-related choice behavior: a math and science perspective. JVB. 2000;57:348-364.

37. Barbaranelli C, Steca P. Autoefficacia nelle scelte di carriera. La valutazione dell'autoefficacia. In: Caprara GV, editor. La valutazione dell'autoefficacia [Assessing Self-Efficacy]. Trento: Edizioni Erickson; 2001:121-136. Italian.

38. Arcuri L, D'Arcais GBF. La misura degli atteggiamenti [The Measure of Attitudes]. Firenze: Giunti e Barbera; 1974. Italian.

39. Capozza DR, Van Order R. Pricing under spatial competition and spatial monopoly. Econometrica. 1977:1329-1338.

40. Osgood CE, Suci GJ, Tannenbaum PH. The Measurement of Meaning. Urbana: University of Illinois Press; 1957:331-369.

41. MacNell L, Driscoll A, Hunt AN. What's in a name: exposing gender bias in student ratings of teaching. JCBA. 2015;10:49.

42. Betz NE. Advances in vocational theories. Handb Couns Psychol. 2008;4:357-374.

43. Harari MB, Viswesvaran C, O'Rourke R. Gender differences in work sample assessments: not all tests are created equal. Revista de Psicología del Trabajo y de las Organizaciones. 2014;30(1):29-34.

35. Wraga M, Duncan L, Jacobs EC, Helt M, Church J. Stereotype susceptibility narrows the gender gap in imagined self-rotation performance. Psychon Bull Rev. 2006;13(5):813-819.

45. Magnano P, Platania S, Ramaci T, Santisi G, Di Nuovo S. Validation of the Italian version of the Mindfulness Organizing Scale (MOS) in organizational contexts. TPM. 2017;24:45-64.

46. Ledda C, Cicciù F, Puglisi B, Ramaci T, Giuseppe Nunnari G, Rapisarda V. Attitude of health care workers (HCWs) to patients affected by HIV/ AIDS and drug addicts: a cross-sectional study. IJERPH. 2017;14(3):284.

47. Zierold KM, Welsh EC, McGeeney TJ. Attitudes of teenagers towards workplace safety training. J Community Health. 2012;37(6):1289-1295.

48. Magnano P, Ramaci T, Platania S. Self-efficacy in learning and scholastic success: implications for vocational guidance. Proc Soc Behav Sci. 2014;116:1232-1236.

49. Pellerone M, Ramaci T, Herrera Lopez M, Craparo G. The role of identity development and decision making process on adult attachment: a cross-national study in Sicilian and Andalusian adolescents. Clin Neuropsychiatry. 2017;14(2):141-150.

50. Magnano P, Santisi G, Ramaci T. Does the metacognitive attitude predict work motivation in Italian teachers? JSS. 2014;2:95-105.

51. Pellerone M, Tomasello G, Migliorisi S. Relationship between parenting, alexithymia and adult attachment styles: a cross-sectional study on a group of adolescents and young adults. Clin Neuropsychiatry. 2017;14(2):125-134.

52. Talib JA, Salleh A, Salleh A, et al. Effect of career education module on career development of community college students. Int J Educ Vocat Guid. 2015;15(1):37-55. 
Psychology Research and Behavior Management is an international, peerreviewed, open access journal focusing on the science of psychology and its application in behavior management to develop improved outcomes in the clinical, educational, sports and business arenas. Specific topics covered in the journal include: Neuroscience, memory and decision making; Behavior modification and management; Clinical applications; Business and sports performance management; Social and developmental studies; Animal studies. The manuscript management system is completely online and includes a very quick and fair peer-review system, which is all easy to use. Visit http://www. dovepress.com/testimonials.php to read real quotes from published authors.

Submit your manuscript here: https://www.dovepress.com/psychology-research-and-behavior-management-journal 